\title{
RANCANG BANGUN ALAT PENGUKUR KECEPATAN AKUSTIK DAN KADAR AIR VOLUMETRIK UNTUK MONITORING TANAH LONGSOR
}

\author{
Ahmad Iqbal Hamami ${ }^{1}$, Dwa Desa Warnana ${ }^{1}$, dan Amien Widodo ${ }^{1}$ \\ ${ }^{1}$ Departemen Teknik Geofisika, Fakultas Teknik Sipil, Perencanaan, dan Kebumian, Institut Teknologi \\ Sepuluh Nopember (ITS) \\ e-mail: iqbalhamami.ahmad@gmail.com
}

\begin{abstract}
Abstrak. Faktor yang dapat memicu terjadinya tanah longsor salah satunya yaitu nilai hambatan geser yang kecil. Hal ini bisa disebabkan karena terdapatnya lapisan kedap air dibawah lapisan jenuh oleh air. Sehingga perlu dilakukan monitoring parameter tanah lain yang berhubungan dengan kadar air volumetrik. Dari data BNPB, dalam 10 tahun terakhir bencana tanah longsor terjadi di Indonesia lebih dari 200 kali setiap tahunnya. Dari total kejadian bencana longsor tersebut mengakibatkan 63 orang meninggal dunia dan hilang, 1625 rumah rusak, dan 37 fasilitas umum rusak. Sedangkan menurut LIPI, hingga saat ini baru terdapat 150 alat deteksi longsor yang terpasang dari ribuan yang dibutuhkan. Sehingga pada penelitian ini akan dibuat prototipe alat untuk monitoring tanah longsor. Penelitian ini akan membahas mengenai aplikasi alat ultrasonic transducers sebagai sistem monitoring kecepatan akustik pada tanah. Ultrasonic transducers adalah metode yang menggunakan 2 sensor ultrasonic dimana satu sensor dihubungkan dengan modul transmitter dan sensor yang lainnya dihubungkan dengan modul receiver, selanjutnya keduanya akan dihubungkan dengan generator gelombang dan mikrokontroler. Transmitter sebagai sensor untuk menghasilkan gelombang suara didalam tanah yang akan diterima oleh receiver. Sehingga didapatkan waktu penjalaran gelombang suara pada jarak tertentu yang telah ditentukan. Dari kedua parameter tersebut dilakukan perhitungan di software Arduino IDE sehingga bisa didapatkan output berupa kecepatan akustik pada tanah. Setelah dilakukan pengujian dengan sudut kemiringan $43^{\circ}$, didapatkan nilai kecepatan akustik saat terdapat rekahan pada pengujian ke-1 naik dari $1309.24 \mathrm{~m} / \mathrm{s}$ ke $1694.34 \mathrm{~m} / \mathrm{s}, 1636.55 \mathrm{~m} / \mathrm{s}$ ke $2117.93 \mathrm{~m} / \mathrm{s}$ pada pengujian ke-2, dan $1505.23 \mathrm{~m} / \mathrm{s}$ ke $2117.93 \mathrm{~m} / \mathrm{s}$ pada pengujian ke-3. Nilai kecepatan akustik relatif turun (semakin kecil) ketika kadar air volumetriknya bertambah. Nilai kadar air volumetrik sendiri terdapat pada rentang $87 \%$ sampai $99 \%$ pada saat terdapat rekahan sampai longsoran total terjadi. Hasil pengujian tanah berdasarkan ukuran butir menunjukkan bahwa jenis tanah yang digunakan pada penelitian ini adalah pasir lempungan.
\end{abstract}

Kata Kunci: Kadar air volumetric; kecepatan akustik; ultrasonic; prototype; longsor.

\begin{abstract}
One of the factors that can trigger the occurrence of landslides is the value of a small sliding resistance which can be caused by the presence of an impermeable layer of water under the saturated layer of water. So monitoring other soil parameters related to volumetric water content is needed. BNPB's data shows that in the last 10 years, landslides has occurres in Indonesia more than 200 times each year. From the data, landslides caused 63 people died and disappeared, 1625 houses damaged, and 37 public facilities damaged. Meanwhile according to LIPI, until now there are only 150 landslide detection devices installed from thousands needed. So this study will made a prototype for landslides monitoring. This study will discuss the application of ultrasonic transducers as an acoustic velocity monitoring system on soil. Ultrasonic transducers is a method that uses 2 ultrasonic sensors where one sensor is connected to the transmitter module and the other sensor is connected to receiver module, both of them will be connected to wave generator and microcontroller. Transmitter as a sensor to produce sound waves in the ground that will be received by the receiver. So the sound wave propagation time is obtained at a specified distance. The two parameters are calculated in the Arduino IDE software, so the output can obtained in the form of acoustic speed in the ground. The experiment with $43^{\circ}$ degree slop showed the acoustic velocity values obtained when there is a fracture with in the first test increased from $1309.24 \mathrm{~m} / \mathrm{s}$ to $1694.34 \mathrm{~m} / \mathrm{s}, 1636.55 \mathrm{~m} / \mathrm{s}$ to $2117.93 \mathrm{~m} / \mathrm{s}$ in the second test, and $1505.23 \mathrm{~m} / \mathrm{s}$ to $2117.93 \mathrm{~m} / \mathrm{s}$ in the third test. The acoustic velocity value relatively decreases (gets smaller) when the volumetric water content increases. The volumetric water content is in the range of $87 \%$ to $99 \%$ since the fracture occurred, until a total landslide occurred. Soil test results based on grain size indicate that the type of soil used in this study is clayley sand.
\end{abstract}

Keywords: Acoustic velocity; landslide; prototype; ultrasonic; volumetric; water content. 


\section{PENDAHULUAN}

Tanah longsor adalah suatu fenomena pergerakan massa batuan, tanah, atau bahan rombakan material penyusun lereng yang bergerak ke bawah atau ke luar lereng karena pengaruh gravitasi (Risdiyanto, 2011). Ada beberapa faktor penyebab tanah longsor dimana salah satunya adalah nilai hambatan geser yang kecil karena terdapatnya lapisan jenuh air diatas lapisan kedap air. Dari data BNPB, lebih dari 200 kali bencana tanah longsor terjadi tiap tahunnya pada 10 tahun terakhir. Pada tahun 2018 sendiri terjadi 281 kali bencana tanah longsor dimana kejadian paling banyak terjadi di Jawa Tengah 102 kali, Jawa Barat 65 kali, dan Jawa Timur 58 kali. Dari total kejadian bencana longsor tersebut mengakibatkan 63 orang meninggal dunia dan hilang, 1625 rumah rusak, dan 37 fasilitas umum rusak (BNPB, 2019). Menurut LIPI, alat pendeteksi tanah longsor yang ada di Indonesia hingga saat ini baru 150 dari total ribuan yang dibutuhkan (LIPI, 2018).

Pada penelitian sebelumnya digunakan pengujian sampel untuk melakukan perhitungan kecepatan akustik dan kadar air menggunakan rumus empiris yang ada. Hasil dari penelitian ini didapatkan grafik hubungan antara kecepatan suara dan kadar air volumetrik pada tanah yang berbanding terbalik (Adamo dkk., 2004). Pada penelitian sebelumnya yang membuat prototipe alat monitoring kecepatan tanah menggunakan multi segment inclinometer, metode ini menggabungkan 2 buah inclinometer berbasis accelerometer dalam 1 lubang bor. Dengan menambahkan jumlah accelerometer yang ditempatkan secara bervariasi terhadap kedalaman, maka didapat pergerakan tanah yang terjadi pada sebaran vertikal. Hasil dari penelitian ini didapatkan nilai perubahan sudut dan kadar air volumetrik sebelum terjadi tanah longsor secara real time (Uchimura dkk., 2015). (Kong dkk., 2017)melakukan penelitian tentang pembuatan sensor (transmitter dan receiver) menggunakan piezoelectric transducers. Sensor tersebut digunakan pada penilitian ini untuk mencari hubungan kadar air volumetrik terhadap penguatan sinyal. Hasil dari penelitian ini menunjukkan bahwa semakin kecil kadar air volumetriknya indeks energi gelombang yang dibutuhkan semakin besar. Dimana pada kadar air volumetrik sebesar 3\% indeks energi yang dibutuhkan sebesar 3,5 × 104 sedangkan pada kadar air volumetrik sebesar $15 \%$ indeks energi yang dibutuhkan sebesar $0,2 \times 10^{4}$.

Penelitian ini akan membahas mengenai aplikasi metode ultrasonic transducers sebagai sistem monitoring kecepatan akustik pada tanah. Ultrasonic transducers adalah alat yang menggunakan 2 sensor ultrasonic dimana satu sensor menjadi transmitter dan sensor yang lainnya menjadi receiver. Transmitter sebagai sensor untuk menghasilkan gelombang suara didalam tanah yang nantinya akan diterima oleh receiver. Sehingga didapatkan waktu penjalaran gelombang suara pada jarak tertentu yang telah ditentukan. Dari kedua parameter tersebut dilakukan perhitungan pada software Arduino IDE sehingga bisa didapatkan output berupa kecepatan akustik pada tanah. Digunakan juga sensor moisture untuk mendapatkan nilai kadar air volumetric. Parameter tersebut akan dianalisis secara real time dan dibandingkan dengan kadar air volumetrik pada tanah, dan digunakan untuk praduga kemungkinan waktu kelongsoran tanah akan terjadi.

\section{Kecepatan Akustik dan Kadar Air Volumetrik}

Menurut Model Brutsaert, 1964 rumus untuk kecepatan gelombang elastis adalah sebagai berikut:

$$
v=\sqrt{\frac{0,306 \cdot a \cdot z \cdot \rho \varepsilon^{\frac{1}{3}}}{\rho \text { tot.f. } \cdot b^{\frac{2}{3}}}}
$$

dengan :

Koefisien $a$ dan $b$ tergantung pada sifat granular dari suatu materi

$f:$ porositas

$Z$ : parameter interstitial efek

ptot : total densitas materi

$\rho e$ : tekanan efektif tanah.

Perlu ditekankan bahwa model kecepatan berlaku sangat baik untuk pengukuran kadar air volumetrik karena parameter Z, ptot dan $\rho e$ dalam (1) semuanya terkait dengan derajat kejenuhan dengan cair, didefinisikan sebagai berikut :

$$
S=\frac{V w}{V v}=\frac{u}{f}
$$

dengan :

$u$ : kelembaban tanah

$\mathrm{Vw}$ : volume air

$\mathrm{V} v$ : volume tanah kering

$S$ : tingkat kadar air volumetrik. 
Persamaan (1) dan (2) merupakan dasar untuk mendapatkan pengukuran kelembaban (kadar air volumetrik) dari pengukuran kecepatan. Ini menunjukkan bahwa kecepatan akustik di tanah bergantung pada tiga parameter, yaitu total massa tanah, tekanan efektif, dan parameter pengantara. Dari penurunan dan substitusi persamaan dari ketiga parameter tersebut didapatkan persamaan kecepatan yang memungkinkan sebagai berikut :

$$
v=\bar{\Psi} \sqrt{\frac{0, a 06, p e \frac{1}{3}}{\rho \operatorname{stot}_{0}}}
$$

dengan :

$\bar{\psi}=\left(a^{1 / 2}\right) /\left(b^{1 / a}\right)$ adalah faktor amplifikasi yang bergantung pada jenis tanah.

Menentukan nilai faktor amplifikasi membutuhkan nilai dari konstantan $a$ dan $b$, tetapi juga bisa ditentukan dengan uji laboratorium tanah. Dari persamaan (3) dapat dilihat bahwa kecepatan akustik akan berkurang ketika tingkat kadar air volumetrik pada tanah meningkat (Adamo dkk., 2004). Untuk grafik hubungan ini dapat dilihat pada gambar 1 berikut.

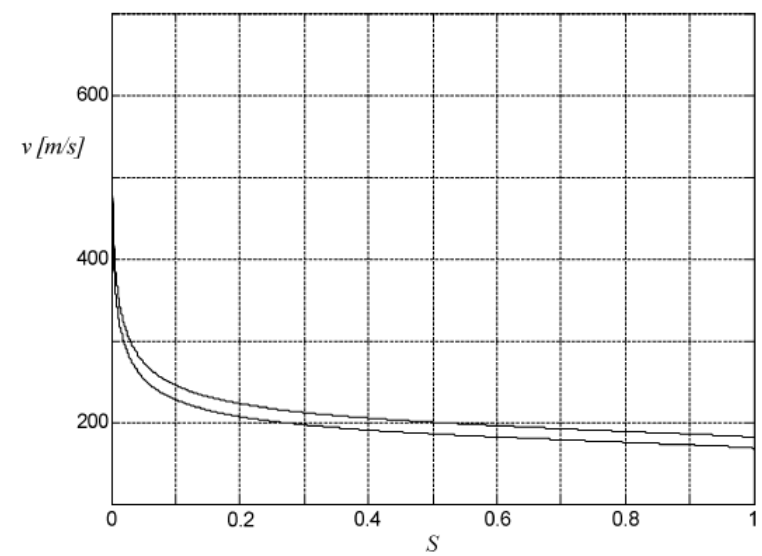

Gambar 1. Grafik Hubungan kecepatan akustik dan kadar air volumetrik pada tanah berdasarkan perhitungan.

\section{Distribusi Ukuran Butir dan Jenis Tanah}

Hasil dari analisis ayakan dan hydrometer digambarkan dalam kertas semilogaritmik yang dikenal sebagai kurva distribusi ukuran-butiran. Diameter partikel (butiran) digambarkan dalam skala logaritmik, dan persentase dari butiran yang lolos ayakan digambarkan dalam skala hitung biasa. Sebagai contoh, grafik distribusi ukuran-butiran dari dua tanah ditunjukkan dalam Gambar 2.

Grafik distribusi ukuran-butiran dari tanah A adalah kombinasi dari hasil analisis ayakan dan hasil analisis hidrometer untuk fraksi halusnya. Bila hasil dari analisis ayakan dan analisis hidrometer digabung, diskontinuitas (discountinuity) umumnya timbul dalam rentang dimana kedua grafik saling bertumpangan.

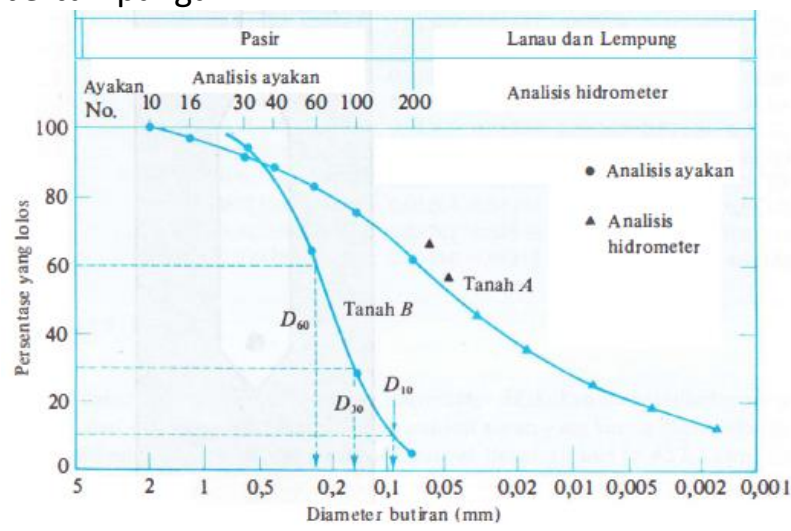

Gambar 2. Contoh kurva distribusi ukuran butir

Persentase dari kerikil, pasir, lanau, dan butiran berukuran lempung yang dikandung oleh tanah dapat-ditentukan dari grafik distribusi ukuranbutiran. Menurut Sistem Klasifikasi Unified (USCS), Tanah A dalam Gambar 2 mempunyai:

- Kerikil (ukuran batas - lebih besar dari 4,75 $\mathrm{mm})=0 \%$

- Pasir (ukuran batas - 4,75 mm sampai dengan $0,075 \mathrm{~mm}$ ) $=$ persentase butiran yang lebih halus dari $4,75 \mathrm{~mm}$ - persentase butiran yang lebih halus dari $0,075 \mathrm{~mm}=1$ $00-62=38 \%$.

- Lanau dan lempung (ukuran batas- kurang dari $0,075 \mathrm{~mm})=62 \%$.

Kurva distribusi ukuran-butiran dapat digunakan untuk membandingkan beberapa jenis tanah yang berbeda-beda. Selain itu ada tiga parameter dasar yang dapat ditentukan dari kurva tersebut, dan parameter-parameter tersebut dapat digunakan untuk mengklasifikasikan tanah berbutir kasar. Parameter-parameter tersebut adalah:

a. ukuran efektif (effective size),

b. koefisien keseragaman (uniformity coefficient),

c. koefisien gradasi (coefficient of gradation).

Diameter dalam kurva distribusi ukuranbutiran yang bersesuaian dengan $10 \%$ yang lebih halus (lolos ayakan) didefinisikan sebagai ukuran efektif, atau D10. Koefisien keseragaman diberikan dengan hubungan:

$$
C u=\frac{D 60}{D 10}
$$

Koefisien gradasi dinyatakan sebagai

$$
C c=\frac{D B 0^{2}}{D 0 \times D 10}
$$

dengan :

$\mathrm{Cu}=$ koefisien keseragaman 
D60 = diameter yang bersesuaian dengan $60 \%$ lolos ayakan.

$\mathrm{Cc}=$ koefisien gradasi

D30 = diameter $\mathrm{y}$ ang bersesuaian dengan $30 \%$ lolos ayakan.

Untuk pengelompokan jenis tanah menurut usgs agar lebih gampangnya dapat dilihat pada gambar 3. (M.Das dkk., 1995)
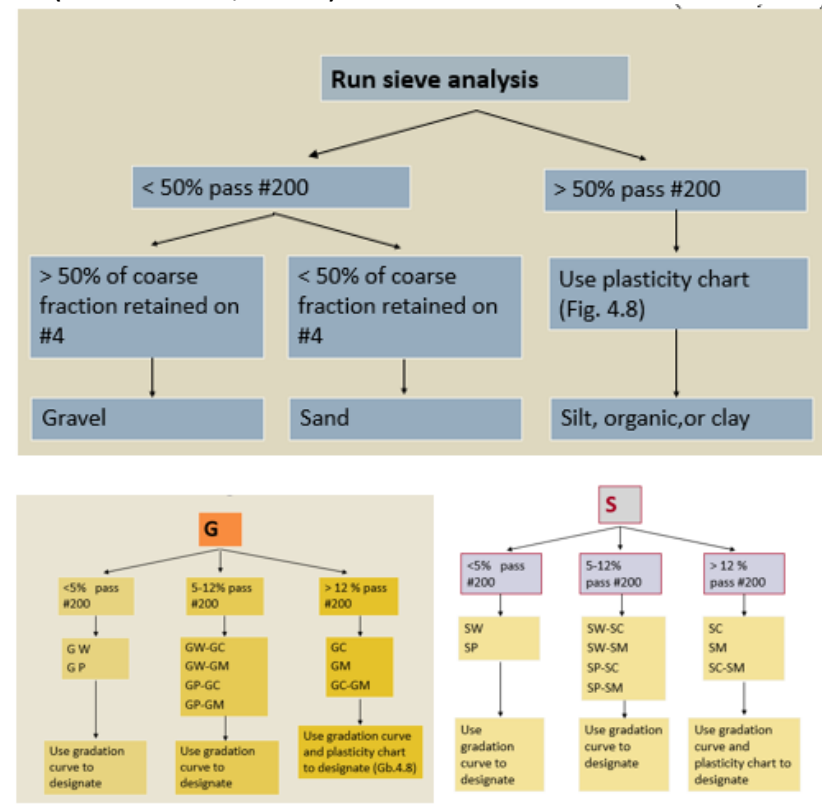

Gambar 3. Pengelompokan jenis tanah menurut USCS berdasarkan ukuran butir

Jenis tanah juga dapat ditentukan berdasarkan nilai kecepatan gelombang kompresional dan dapat dilihat pada tabel 1 .

Tabel 1. Jenis tanah berdasarkan Vp (Verhoef, 1989)

\begin{tabular}{|c|c|c|}
\hline \multirow{4}{*}{ Nama Material } & $\mathrm{Vp}(\mathrm{m} / \mathrm{s})$ \\
\hline \multirow{4}{*}{ Tanah } & Alluvial & $500-2100$ \\
\cline { 2 - 3 } & Lempung & $1100-2500$ \\
\cline { 2 - 3 } & Loss & $300-600$ \\
\cline { 2 - 3 } & Pasir & $200-2000$ \\
\cline { 2 - 3 } & Napal Bongkah & $400-1700$ \\
\hline \multirow{5}{*}{ Batu } & Granit & $4600-6000$ \\
\cline { 2 - 3 } & Gaabro, dolerite, & $5000-6700$ \\
\cline { 2 - 3 } & basalat & $1400-4500$ \\
\cline { 2 - 3 } & Batu Pasir, Serpih & $1700-4200$ \\
\cline { 2 - 3 } & Batu Kapur, lembek & $2800-6400$ \\
\cline { 2 - 3 } & Batu Kapur, Kokoh & $5700-6400$ \\
\cline { 2 - 3 } & Marmer & $3600-4400$ \\
\cline { 2 - 3 } & Sabak & $3500-7500$ \\
\cline { 2 - 3 } & Skiis, gneiss & \\
\hline
\end{tabular}

\section{METODOLOGI}

Alur pada penelitian ini dijelaskan melalui diagram alir penelitian pada Gambar 4 dibawah ini.

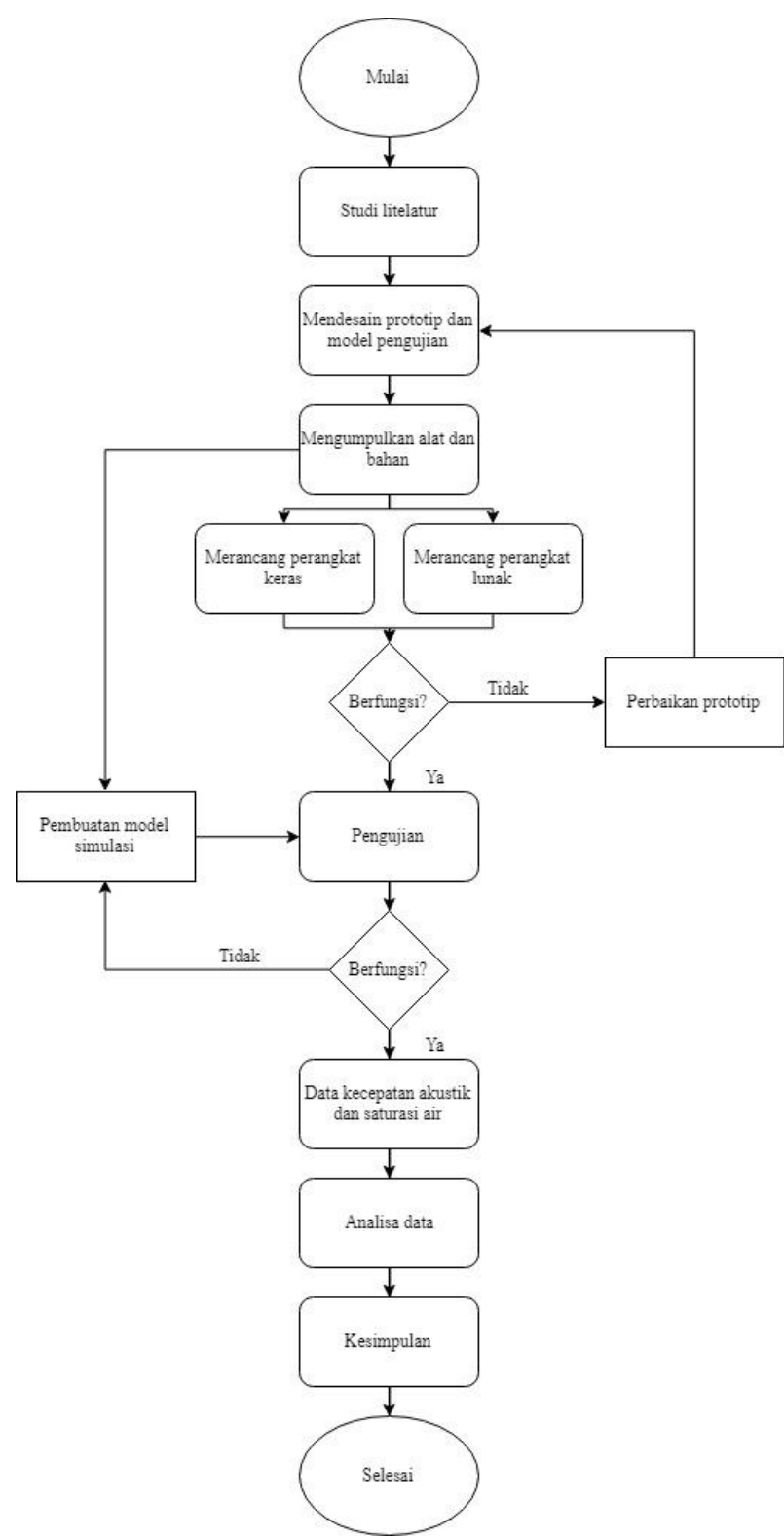

Gambar 4. Diagram alir penelitian

\section{Rancangan Desain dan Pembuatan Alat}

Prinsip kerja dari sistem monitoring yang dibangun pada penelitian ini yaitu menentukan nilai kecepatan akustik tanah dari output yang dikeluarkan oleh ultrasonic dan wavelet generator. Skema prinsip alat ini dijelaskan melalui Gambar 2.

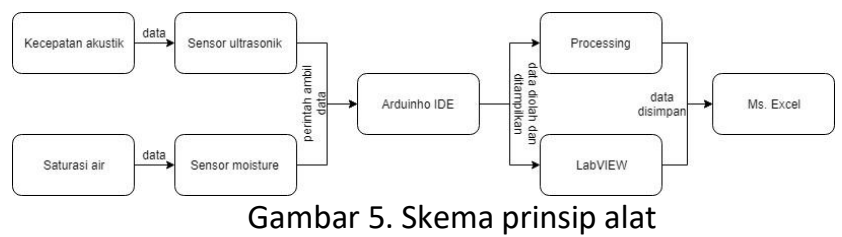

Ketika terjadi perubahan kadar air volumetrik pada tanah dimana itu merupakan salah satu faktor 
terjadinya longsor, maka hasil dari prototipe ini (kecepatan akustik) akan berubah seiring bertambahnya kadar air volumetrik. Data kadar air volumetrik akan didapatkan dari sensor kelembaban (moisture). Parameter kecepatan dan kelembaban (kadar air volumetrik) itu akan dianalisa dan dibandingkan keterkaitannya sampai terjadi longsoran tanah. Hasil akhirnya didapatkan hubungan kecepatan dan kelembaban saat akan terjadi longsoran.

\section{Perancangan Hardware}

Perancangan hardware terdiri dari lima rangkaian utama yaitu rangkaian catu daya, rangkaian generator gelombang, rangkaian penerima gelombang, rangkaian penguat gelombang, dan mikrokontroler. Rangkaian catu daya terdiri dari output daya $48 \mathrm{~V}$ dan $12 \mathrm{~V}$ dan berfungsi sebagai sumber daya untuk rangkaian generator gelombang (48 V) dan juga rangkaian penerima gelombang (12V). Skematik rangkaian catu daya dapat dilihat pada gambar 6 .
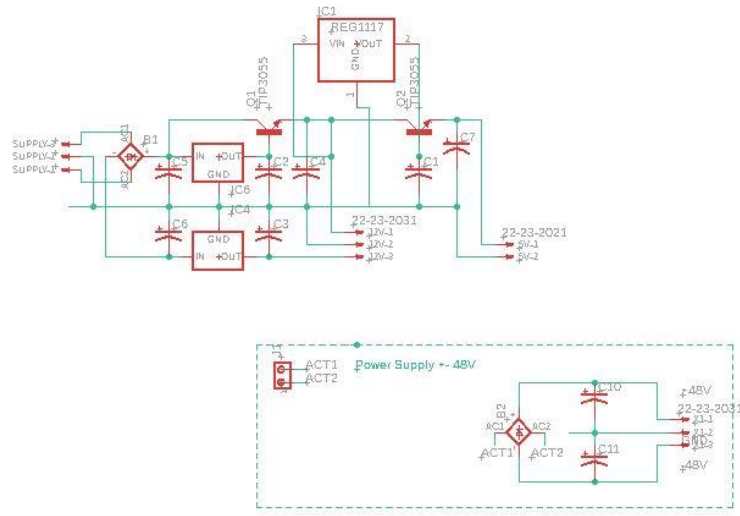

Gambar 6. Skematik rangkaian catu daya

Rangkaian generator gelombang berfungsi sebagai penembak gelombang sinusoidal $3.3 \mathrm{~V}$. Sedangkan rangkaian penerima gelombang berfungsi untuk memroses serta sebagai penguat 10 kali gelombang sinusoidal yang diterima. Kedua rangkaian ini yang nantinya akan disambungkan langsung ke Arduino DUE sebagai mikrokontroler (arduino shield). Skematik rangkaian arduinho shield dapat dilihat pada gambar 7 .

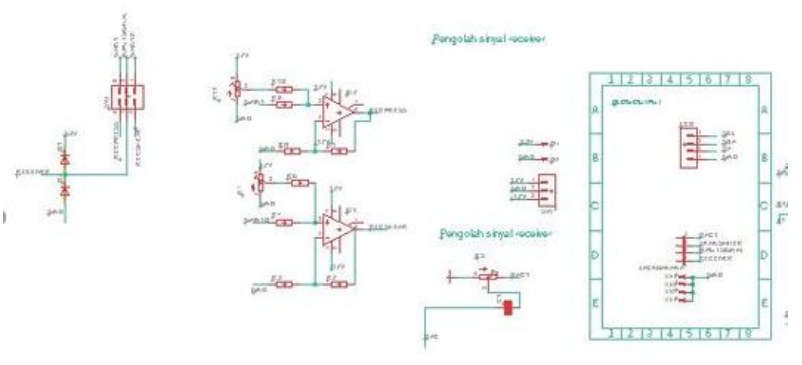

Gambar 7. Skematik rangkaian penerima dan generator gelombang

Rangkaian penguat gelombang $60 \mathrm{~V}$ berfungsi untuk menguatkan sinyal sinusoidal sebesar 3,3 volt menjadi 60 volt peak to peak sebelum masuk ke transmitter ultrasonic. Tegangan 60 volt digunakan agar sinyal ultrasonic dapat menembus spesimen berupa tanah. Dikarenakan jika hanya menggunakan gelombang yang memiliki tegangan sebesar 3.3 volt tidak mampu menembus medium tanah, sehingga menyebabkan receivernya tidak dapat menerima gelombang yang menjalar.

Perancangan hardware kadar air volumetrik terdiri dari 2 rangkaian yaitu mikrokontroler dan juga modul sensor kelembababan. Sensor kelembaban, akan menghitung perubahan nilai output pada sensor akibat dari perubahan kadar air. Sensor ini akan mengukur konstanta dielektrik dari tanah yang merupakan parameter yang sensitif terhadap kandungan air pada tanah. Diperlukan perhitungan dari nilai output sensor untuk mendapatkan nilai kadar air dalam bentuk persentase. Rangkaian kadar air dapat dilihat pada gambar 8.

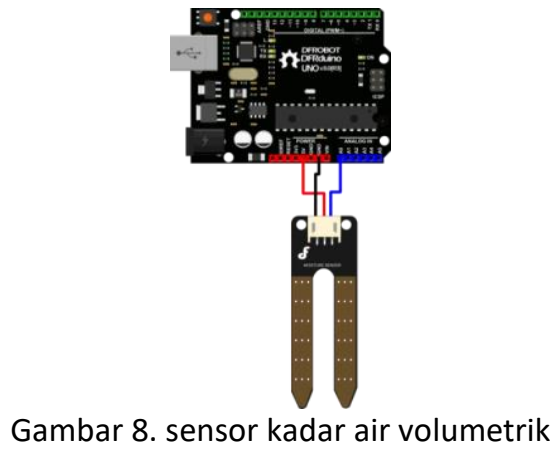

\section{Pengujian Alat}

Pengujian alat akan dilakukan pada model longsor skala laboratorium dengan dimensi panjang $70 \mathrm{~cm}$, lebar $35 \mathrm{~cm}$, dan tinggi $28 \mathrm{~cm}$. 


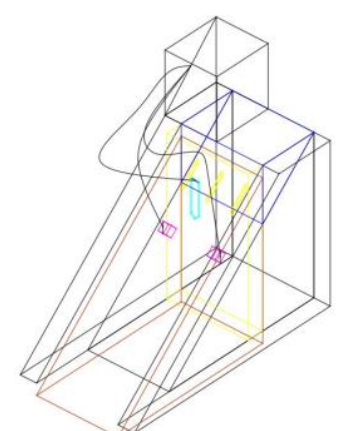

(a)

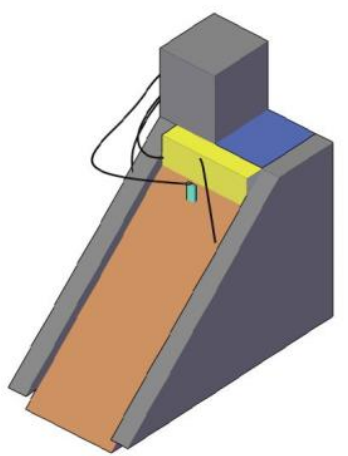

(b)
Gambar 9 (a) Peletakan sensor pada model longsor (b) Model pengujian ketika sudah terisi tanah

Peletakan sensor dapat dilihat seperti gambar 9 (a). Tanah yang akan dipakai pada model ini berupa tanah pasir lempugan yang nantinya akan diukur perbandingan pasir dan lempungnya, dikarenakan jenis tanah ini yang banyak terdapat pada daerah rawan longsor. Variasi yang akan dipakai adalah penambahan kadar air dengan sudut yang digunakan tetap yaitu sebesar $43^{\circ}$. Menurut Afif, 2019 ketika hanya parameter sudut yang dipakai untuk monitoring terjadinya longsoran, sudut $43^{\circ}$ inilah sudut kritis yang didapatkan sebelum terjadinya longsoran. Hasil akhir dari pengujian ini nantinya akan didapatkan data perbandingan nilai kecepatan akustik terhadap kadar air volumetrik.

\section{HASIL DAN PEMBAHASAN \\ Pengujian Tanah}

Sebelum dilakukan pengujian pada model longsor, dilakukan terlebih dahulu pengujian tanah berdasarkan besar butirnya. Hasil dari pengujian tanah ini dapat dilihat pada tabel 2 berikut.

Tabel 2. Hasil uji tanah menggunakan ayakan

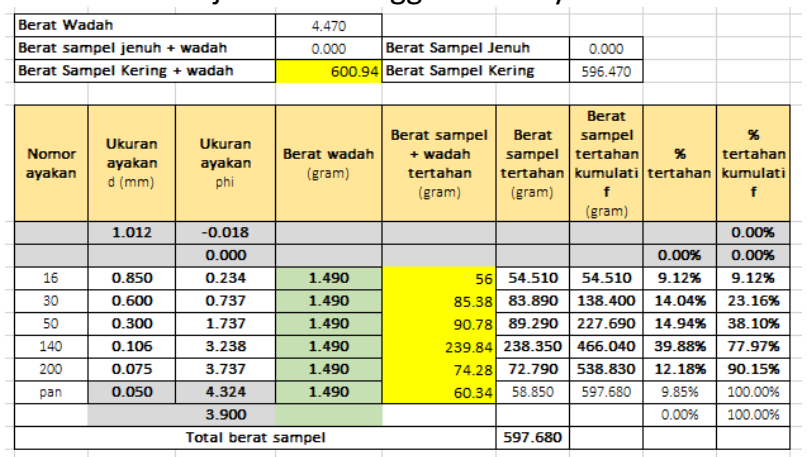

Dari hasil ayakan tersebut dapat dilakukan klasifikasi tanah berdasarkan USCS. Dari gambar 2 dapat dilihat bahwa jenis tanah ini merupakan pasir, dikarenakan kurang dari $50 \%$ yang lolos ayakan nomor 200 dan kurang dari $50 \%$ juga tertahan di ayakan nomor 4. Dikatakan kurang $50 \%$ yang tertahan diayakan nomor 4 padahal tidak digunakan ayakan nomor 4 karena pada ayakan nomor 16 yang memiliki ukuran ayakan lebih kecil dari ayakan nomor 4 , yang tertahan hanya $9,12 \%$. Kemudian dilihat kelolosan pada ayakan nomor 200 dimana berada pada angka 5-12\%, yang menunjukkan pasir ini salah satu jenis dari pasir lempungan dengan gradasi baik (SW-SC), pasir lanauan dengan gradasi baik (SW-SM), pasir lempungan dengan gradasi buruk (SP-SC), atau pasir lanauan dengan gradasi buruk (SP-SM). Untuk mengetahui jenisnya secara spesifik, maka berdasarkan kurva distribusi ukuran butir pada gambar 10 dilakukan perhitungan koefisien keseragaman $(\mathrm{Cu})$ dan koefisien gradasi (Cc) untuk mengetahui distribusi ukuran butir.

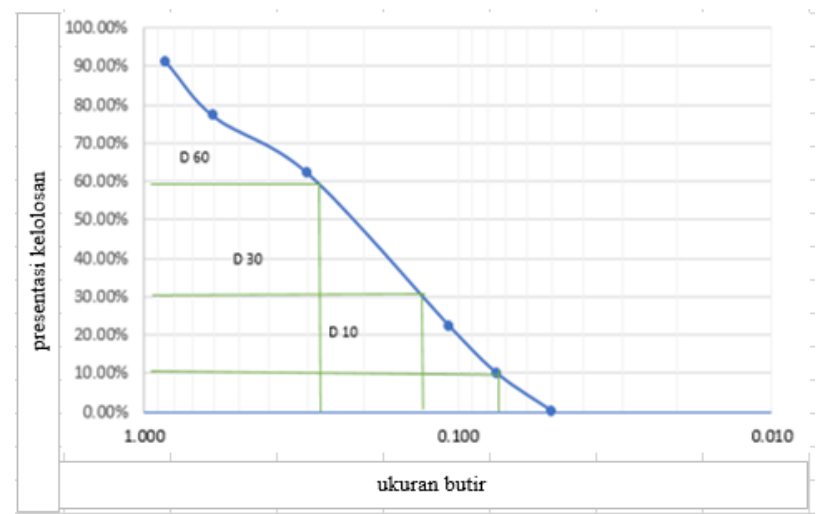

Gambar 10. Kurva distribusi ukuran butir

Berdasarkan persamaan (4) dan (5) didapatkan nilai koefisien keseragaman (Cu) sebesar 3.89 dan koefisien gradasi (Cc) sebesar 1.269. Berdasarkan nilai koefisien keseragaman dan koefisien gradasi tersebut tanah ini berjenis pasir lempungan dengan gradasi buruk (SP-SC). Menurut USCS dari kurva distribusi ukuran butir pada gambar 9 juga dapat dilakukan perhitungan besar kandungan pasir dan jumlah lempungnya.

- Kerikil (ukuran batas - lebih besar dari 4,75 $\mathrm{mm})=0 \%$

- Pasir (ukuran batas - 4,75 mm sampai dengan $0,075 \mathrm{~mm}$ ) $=$ persentase butiran 
yang lebih halus dari $4,75 \mathrm{~mm}$ - persentase butiran yang lebih halus dari $0,075 \mathrm{~mm}=$ $100-9.9=90.1 \%$.

Lanau dan lempung (ukuran batas kurang dari 0,075 $\mathrm{mm})=9.9 \%$

\section{Pengujian Longsor}

Telah dilakukan pengujian prototipe pada model longsor yang dibuat seperti gambar 8 (b). pengujian dilakukan dengan 3 kali pengulangan agar didapatkan data yang lebih baik. Pengujian pertama dilakukan pada tanggal 25 Mei 2019 mulai pukul 13:39:29 sampai dengan pukul 14:07:42. Pengujian ke-2 pada tanggal 28 Mei 2019 mulai pukul 11:12:33 sampai pukul 11:20:54, dan pengujian ke-3 pada hari yang sama mulai pukul 11:48:08 sampai pukul 11:50:55. Hasil dari pengujian ini dapat dilihat seperti tabel 3 berikut.

Tabel 3. Data hasil pengujian model longsor

\begin{tabular}{|c|c|c|c|}
\hline Waktu & Tanggal & $\begin{array}{c}\text { Kadar air } \\
\text { volumetrik }(\%)\end{array}$ & $\mathbf{V p}(\mathbf{m} / \mathbf{s})$ \\
\hline \multicolumn{4}{|c|}{ Pengujian ke-1 } \\
\hline $13: 39: 29$ & $25-5-2019$ & 4 & 1600.2 \\
\hline $13: 40: 19$ & $25-5-2019$ & 5 & 1600.2 \\
\hline 13:43:00 & $25-5-2019$ & 40 & 1515.98 \\
\hline $13: 43: 15$ & $25-5-2019$ & 57 & 1440.18 \\
\hline $13: 46: 07$ & $25-5-2019$ & 65 & 1404.7 \\
\hline $13: 46: 10$ & $25-5-2019$ & 78 & 1309.24 \\
\hline $13: 48: 05$ & $25-5-2019$ & 87 & 1694.34 \\
\hline 13:58:59 & $25-5-2019$ & 91 & 1694.34 \\
\hline 13:58:59 & $25-5-2019$ & 91 & 1694.34 \\
\hline 13:59:00 & $25-5-2019$ & 91 & 1694.34 \\
\hline 13:59:00 & $25-5-2019$ & 93 & 1694.34 \\
\hline $14: 07: 29$ & $25-5-2019$ & 94 & 1694.34 \\
\hline $14: 07: 42$ & $25-5-2019$ & 65 & 423 \\
\hline \multicolumn{4}{|c|}{ Pengujian ke-2 } \\
\hline $11: 12: 33$ & $28-5-2019$ & 5 & 2000.26 \\
\hline $11: 16: 33$ & $28-5-2019$ & 31 & 1800.22 \\
\hline $11: 17: 11$ & $28-5-2019$ & 35 & 1800.22 \\
\hline 11:18:05 & $28-5-2019$ & 92 & 1636.55 \\
\hline 11:19:18 & $28-5-2019$ & 93 & 1636.55 \\
\hline $11: 20: 18$ & $28-5-2019$ & 95 & 2117.93 \\
\hline 11:20:35 & $28-5-2019$ & 97 & 2117.93 \\
\hline $11: 20: 51$ & $28-5-2019$ & 99 & 2117.93 \\
\hline $11: 20: 54$ & $28-5-2019$ & 103 & 2117.93 \\
\hline \multicolumn{4}{|c|}{ Pengujian ke-3 } \\
\hline 11:48:08 & $28-5-2019$ & 4 & 2000.26 \\
\hline $11: 48: 23$ & $28-5-2019$ & 20 & 1800.22 \\
\hline 11:49:00 & $28-5-2019$ & 45 & 1612.65 \\
\hline 11:49:06 & $28-5-2019$ & 63 & 1570.31 \\
\hline $11: 49: 59$ & $28-5-2019$ & 78 & 1505.23 \\
\hline $11: 50: 13$ & $28-5-2019$ & 92 & 2117.93 \\
\hline
\end{tabular}

Artikel diterima .... 2020, Revisi ........ Online http://dx.doi.org/10.12962/j25023659.v6i2.5410
Berdasarkan tabel 3 dapat dilihat bahwa didapatkan data dari 3 kali hasil pengujian. Data yang didapat yaitu waktu, tangga, nilai kadar air volumetrik, dan nilai kecepatan akustik (Vp). Dari range nilai kecepatan akustik yang didapatkan yaitu $1400-2100 \mathrm{~m} / \mathrm{s}$ jika melihat tabel 1 masuk dalam jenis tanah pasir dan lempung, dimana hal ini seusai dengan uji tanah yang telah dilakukan. Warna putih menunjukkan kondisi tanah ditambahkan air dan tidak terjadi apa-apa. Warna biru menandakan ketika terdapat retakan tanah pada model longsor. Sedangkan warna hijau yang dimana hanya terjadi pada pengujian pertama menunjukkan saat longsor sudah terjadi seluruhnya.

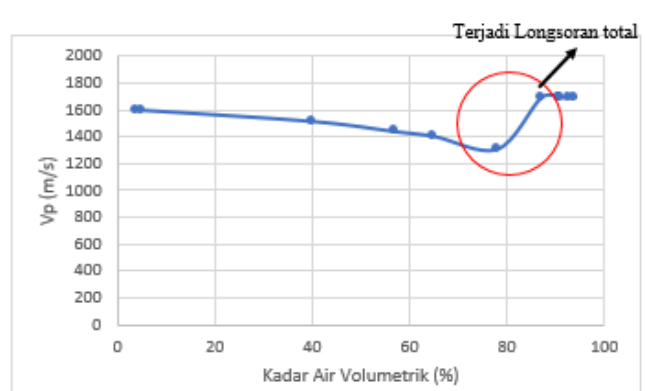

Gambar 11. Grafik hasil pengujian ke-1 kecepatan akustik terhadap kadar air volumetrik

Setelah didapatkan data seperti pada tabel 3, dilakukan plot grafik antara nilai kecepatan akustik terhadap kadar air volumetrik. Hasil plot grafik data pengujian ke-1 dapat dilihat pada gambar 11. Dari grafik dapat dilihat bahwa semakin tanah terkadar air volumetrik, nilai kecepatan akustik gelombang akan semakin kecil. Hal ini sesuai dengan penelitian sebelumnya yang dilakukan oleh (Kong dkk., 2017) dimana pada penelitiannya energi gelombang yang diterima juga semakin kecil ketika kadar air volumetrik semakin bertambah. Hal ini disebabkan karena gelombang akustik yang merambat akan terabsorbsi oleh air yang meresap. Menurut perhitungan dari persamaan yang dikembangkan oleh (Adamo dkk., 2004) juga menunjukkan ketika kadar air volumetrik semakin bertambah maka kecepatan akustik semakin kecil. Dari analisis yang dilakukan, dapat diinterpretasikan nilai kecepatan tanah semakin kecil seiring bertambahnya kadar air 
volumetrik dikarenakan ketika tanah yang padat ditambah oleh air maka tanah akan menjadi lebih gembur. Padahal kecepatan gelombang akustik berbanding lurus dengan kepadatan tanah. Sehingga ketika semakin betambah air tanah akan semakin gembur dan akibatnya kecepatan akustik menjadi semakin kecil.

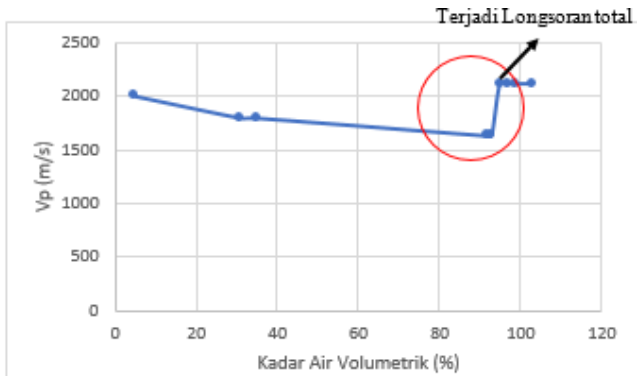

Gambar 12. Grafik hasil pengujian ke-2 kecepatan akustik terhadap kadar air volumetrik

Anomali didapatkan pada saat pengujian, yaitu ketika pada model longsor terbentuk rekahan (crack) yaitu ketika pada tanggal 25 Mei 2019 pukul 13:48:05 pada pengujian ke-1, tanggal 28 pukul 11:20:18 pada pengujian ke-2, dan tanggal 28 pukul 11:50:13 pada pengujian ke-3. Anomali ini terjadi pada semua pengujian yang dilakukan yaitu pengujian 1 sampai 3 . Pada pengujian ke-1 didapatkan kenaikan nilai kecepatan akustik dari $1309.24 \mathrm{~m} / \mathrm{s}$ menjadi $1694.34 \mathrm{~m} / \mathrm{s}, 1636.55 \mathrm{~m} / \mathrm{s}$ menjadi $2117.93 \mathrm{~m} / \mathrm{s}$ pada pengujian ke-2, dan $1505.23 \mathrm{~m} / \mathrm{s}$ menjadi $2117.93 \mathrm{~m} / \mathrm{s}$ pada pengujian ke-3. Hal ini dapat dibuktikan dengan gambar 11, 12, dan 11. Dari ketiga grafik tersebut dapat dilihat bahwa anomali terdapat pada perubahan nilai kecepatan akustik terhadap penambahan kadar air volumetrik (lingkaran merah). Hasil ini menunjukkan bahwa ketika rekahan terbentuk nilai kecepatan akustik akan cenderung lebih besar dan berubah secara drastis. Hal ini kemungkinan terjadi karena keambiguitasan gelombang ultrasonic. Menurut Mavko, 2009 saat beralih dari tanah kering ke tanah jenuh air nilai kecepatan akustik terkadang naik dan terkadang turun. Karena kecepatan akustik sangat bergantung pada modulus elastisitas dan densitas suatu material. Sehingga kedua parameter itu akan saling bertabrakan/menjatuhkan satu sama lain yang menyebabkan nilai kecepatan naik dan turun. Nilai kecepatan akustik yang naik saat terjadi rekahan diinterpretasikan disebabkan karena sudah ada perubahan bentuk dari material tanah (tanah mulai bergerak). Sehingga menyebabkan nilai densitas total berkurang secara drastis.

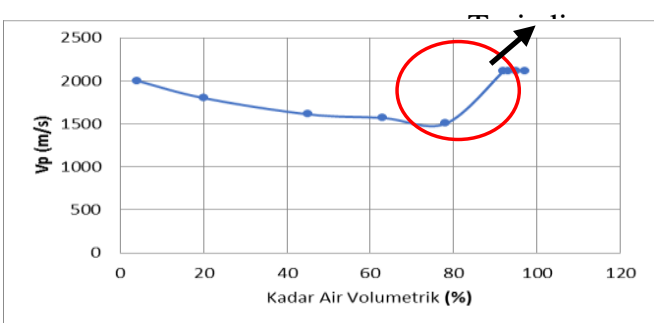

Gambar 13. Grafik hasil pengujian ke-3 kecepatan akustik terhadap kadar air volumetrik

Nilai kadar air volumetrik sendiri terdapat pada rentang $87 \%$ sampai $103 \%$ pada saat terdapat rekahan sampai longsoran total terjadi. Nilai saturasi diatas $100 \%$ terjadi akibat kekeliruan pada saat kalibrasi sensor. Pada datasheet sensor disebutkan untuk menentukan kadar air volumetrik $0 \%$ adalah ketika berada di udara dengan kondisi sensor kering dan $100 \%$ pada kondisi dicelupkan kedalam air. Kondisi ini ternyata berbeda pada saat pengujian, dikarenakan sensor ditempatkan pada tanah yang basah dimana sensor dilingkupi oleh tanah yang jenuh air. Sensor yang dilingkupi tanah yang jenuh air memiliki nilai output yang lebih besar daripada ketika dicelupkan kedalam air.

Kualitas sensor juga sangat berpengaruh dalam pengujian longsor ini, sehingga untuk mendapatkan hasil yang lebih baik disarankan digunakan sensor dengan kualitas yang lebih baik pula.

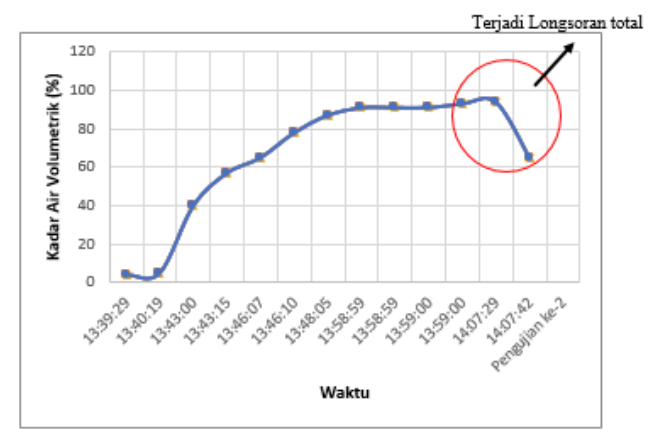

Gambar 14. Grafik kadar air volumetrik berbanding waktu (pengujian 1) 


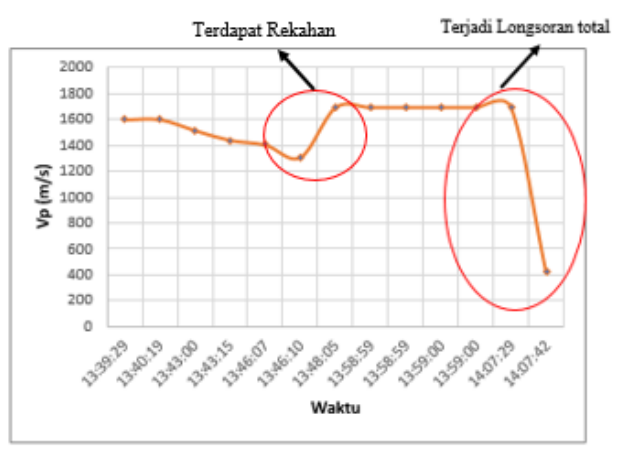

Gambar 15. Grafik Vp berbanding waktu (pengujian 1)

Ketika terjadi longsoran penuh nilai kecepatan akustik dan kadar air volumetrik turun (lingkaran merah pada gambar 14 dan 15). Pada pengujian pertama nilai kecepatan akustik menjadi $423 \mathrm{~m} / \mathrm{s}$ dan kadar air volumetrik turun menjadi 65 . Hal ini terjadi karena diantara sensor sudah tidak ada medium berupa tanah melainkan berganti ke udara. Nilai kecepatan akustik itu sudah sesuia dengan nilai kecepatan akustik di udara, sedangkan nilai kadar air volumetrik masih relative besar kemungkinan karena terdapat air yang menempel pada sisi sensor.

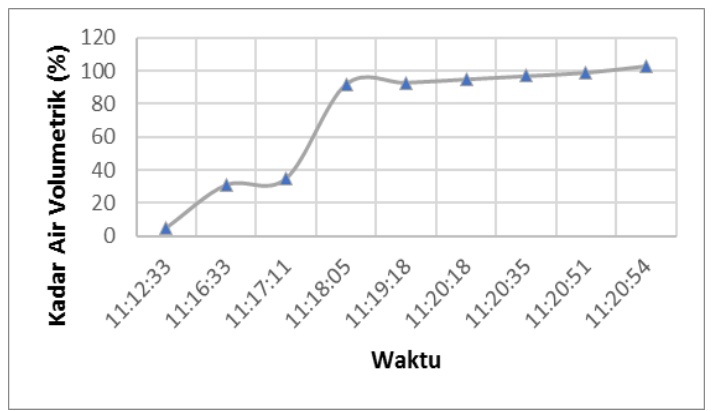

Gambar 16. Grafik kadar air volumetrik berbanding waktu (pengujian 2)

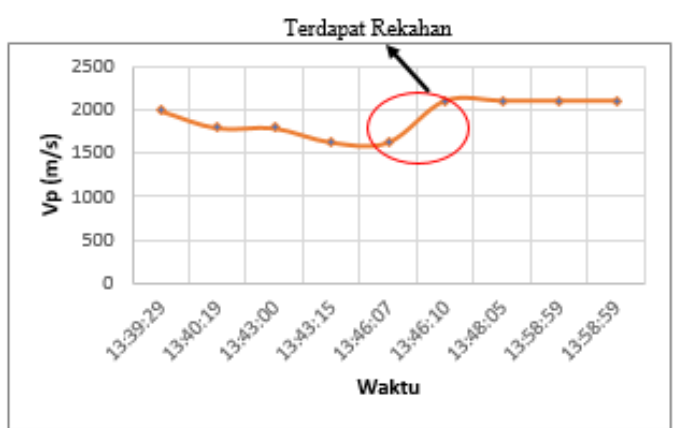

Gambar 17. Grafik Vp berbanding waktu (pengujian 2)

Pada pengujian kedua yaitu gambar 16 dan 17 tidak ditemukan tren turun pada grafik kecepatan akustik Artikel diterima ..... 2020, Revisi Online http://dx.doi.org/10.12962/j25023659.v6i2.5410 dan kadar air volumetrik. Hal ini disebabkan karena saat longsoran terjadi sensor yang terpasang ikut turun dengan tanah dan menyebabkan kabel penghubung antar alat dan sensor putus.

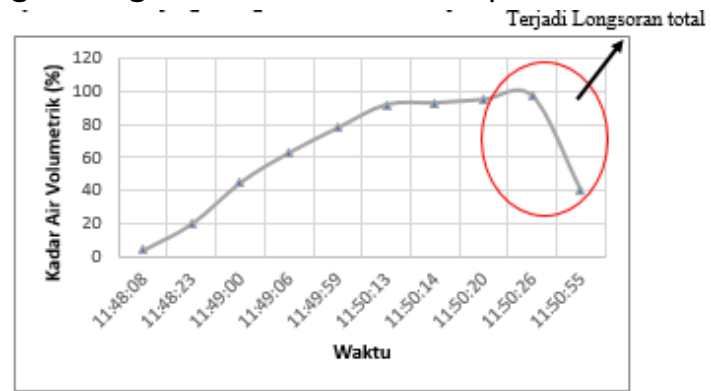

Gambar 18. Grafik kadar air volumetrik berbanding waktu (pengujian 3)

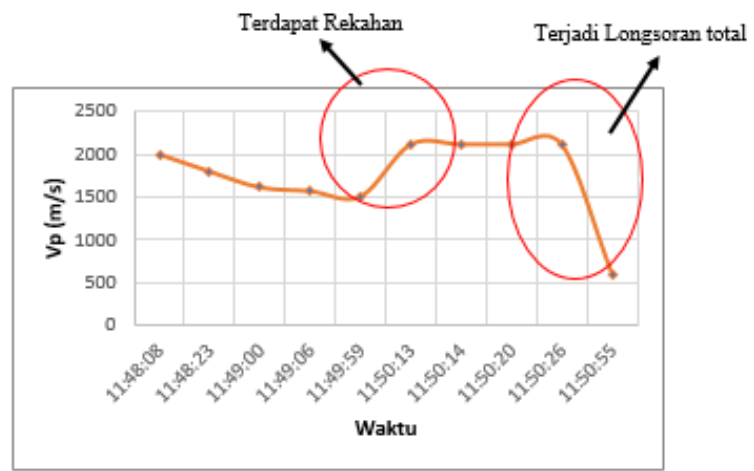

Gambar 19. Grafik Vp berbanding waktu (pengujian 3)

Pada pengujian pertama yang dimulai pukul 13:39:29 longsoran terjadi pada pukul 14:07:42 dimana lama waktu untuk terjadinya longsor 28 menit 13 detik. Pada pengujian ke-2 mulai pukul 11:12:33 dan longsoran terjadi pada pukul 11:20:54 dengan lama waktu 8 menit 21 detik. Pada pengujian ke-3 mulai pukul 11:48:08 dan longsoran terjadi pada pukul 11:50:26 dengan lama waktu 2 menit 18 detik. Perbedaan waktu terjadinya longsor ini disebabkan karena pemberian air yang dilakukan pada setiap pengujian memiliki intensitas yang berbeda-beda. Sehingga diharapkan pada pengujian dengan pemberian intensitas air yang berbeda, data kecepatan akustik saat akan terjadi longsor memiliki nilai yang cenderung sama. Dari data pada tabel 3 memang didapatkan data kecepatan akustik dengan tren yang relatif sama.

\section{PENUTUP}

\section{Simpulan}

Berdasarkan penelitian yang sudah dilakukan, ada beberapa kesimpulan yang didapat, yaitu 
1. Prototipe alat yang dibuat dapat bekerja dan menampilkan bentuk gelombang dengan baik ketika digunakan pengujian pada model longsor.

2. Nilai kecepatan akustik saat terjadi rekahan cenderung naik dimana pada pengujian ke-1 naik dari $1309.24 \mathrm{~m} / \mathrm{s}$ menjadi $1694.34 \mathrm{~m} / \mathrm{s}, 1636.55$ $\mathrm{m} / \mathrm{s}$ menjadi $2117.93 \mathrm{~m} / \mathrm{s}$ pada pengujian ke-2, dan $1505.23 \mathrm{~m} / \mathrm{s}$ menjadi $2117.93 \mathrm{~m} / \mathrm{s}$ pada pengujian ke-3. Nilai kadar air volumetrik sendiri terdapat pada rentang $87 \%$ sampai $99 \%$ pada saat terdapat rekahan sampai longsoran total terjadi

3. Nilai kecepatan akustik relatif turun (semakin kecil) ketika kadar air volumetriknya bertambah.

\section{Saran}

Berdasarkan penelitian yang telah dilakukan, diberikan beberapa saran ketika penelitian akan dikembangkan lebih lanjut, yaitu

1. Sensor kecepatan akustik menggunakan sensor dengan sensitivitas yang lebih tinggi.

2. Dilakukan pengembangan lebih lanjut untuk mendapatkan nilai kecepatan akustik shear (Vs).

3. Menambahkan variabel yaitu jenis tanah yang digunakan untuk pengujian longsor.

\section{Ucapan Terima Kasih}

Penulis mengucapkan terimakasih kepada Departemen Teknik Geofisika ITS yang telah berkontribusi dalam penyelesaian penelitian ini. Juga kepada pihak yang membantu dalam proses pengujian alat.

\section{DAFTAR PUSTAKA}

Adamo, F., Andria, G., Attivissimo, F. dan Giaquinto, N. (2004), "An Acoustic Method for Soil Moisture Measurement", IEEE Transactions on Instrumentation and Measurement, Vol.53, No.4, hal. 891-898. http://doi.org/10.1109/TIM.2004.831126.

Afif, H. (2019), "Aplikasi Multi Segment Inclinometer Berbasis Accelerometer Dan Moisture Sensor Sebagai Sistem Monitoring Pergerakan Tanah", Jurnal Geosaintek, Vol.5, No.1, hal. 25. http://doi.org/10.12962/j25023659.v5i1.4732.

BNPB (2019), Data Informasi Bencana Indonesia (DIBI). Diambil 30 Agustus 2020, dari http://bnpb.cloud/dibi/xdibi_list.
Kong, Q., Chen, H., Mo, Y. dan Song, G. (2017), "RealTime Monitoring of Water Content in Sandy Soil Using Shear Mode Piezoceramic Transducers and Active Sensing-A Feasibility Study", Sensors, Vol.17, No.10, hal. 2395. http://doi.org/10.3390/s17102395.

LIPI (2018), DETEKSI DINI LONGSOR MINIM. Diambil 20 Januari 2019, dari http://geotek.lipi.go.id/?p=8900.

Mavko, G. (n.d.), 4. Seismic Velocity, hal. 40.

M.Das, B., Endah, N. dan Mochtar, I.B. (1995), Mekanika Tanah (Prinsip-prinsip Rekayasa Geoteknis), 1, Erlangga, Indonesia. Diambil dari https://docplayer.info/47070149-Mekanikatanah-prinsip-prinsip-rekayasa-geoteknis.html.

Risdiyanto, I. (2011), "Identifikasi Daerah Rawan Longsor", Institut Pertanian Bogor, Vol.10.

Uchimura, T., Towhata, I., Wang, L., Nishie, S., Yamaguchi, H., Seko, I. dan Qiao, J. (2015), "Precaution and Early Warning of Surface Failure of Slopes Using Tilt Sensors", Soils and Foundations, Vol.55, No.5, hal. 1086-1099. http://doi.org/10.1016/j.sandf.2015.09.010.

Verhoef, P.N.W. (1989), Geologi untuk teknik sipil, Erlangga. 